\title{
Síntese, Espectroscopia e Tingimento com Corantes: o Índigo
}

\author{
J. SEIXAS DE MELO ${ }^{*}$ E MÓNICA B ARROSO
}

0 ESTIMULAR DO ALUNO NA REALIZAÇĀO prática de um trabalho laboratorial é, cada vez mais, uma situação comum com que um docente de química se depara. O presente trabalho, pretende introduzir interdisciplinaridade e incentivo na realização prática do mesmo.

O trabalho encontra-se dividido em três parte segmentadas da seguinte forma:

1) Síntese do corante Índigo. Identificação do mesmo por espectroscopia de IV, UVNis e por cromatografia de camada fina (TLC). A identificação espectroscópica é realizada por comparação com os existentes na literatura, fazendo-se a atribuição das bandas fundamentais. A identificação por TLC é realizada por comparação directa com o corante extraído, de um tecido de ganga azul.

\section{2) Identificação do Índigo e das suas formas cetónica e enólica}

Em solução, o Índigo possui uma forma cetónica e uma forma leuco. Esta última pode ser obtida por redução da primeira com ditionito de sódio em meio básico. As cores de uma e de outra forma são diferentes e, consequentemente, o isomerismo ceto-enólico pode também ser observado por absorção UVNis.

3) Tingimento, com os corantes obtidos, de tecidos de seda, lã e algodão. Uma aplicação prática final dos produtos sintetizados consiste no tingimento de alguns tecidos com os corantes sintetizados.

O tingimento resulta de uma aplicação directa do ponto anterior, uma vez que apenas a forma leuco é solúvel em meio aquoso, necessário ao processo de tin- gimento. Desta forma, o isomerismo pode também ser observado em tecidos (de lã, algodão, seda, etc), no próprio processo de tingimento, pela observação da passagem da cor amarela (forma leuco) para azul (forma ceto) por oxidação induzida pelo oxigénio atmosférico.

\section{Introdução}

\section{Breve Nota Histórica}

O Índigo é, dos corantes importantes da antiguidade, talvez o único que ainda possui aplicações visíveis, nos dias de hoje.

O Indigo, tal como o nome deixa entender, tem as suas origens na İndia antiga. Nas antigas civilizações do Egipto, Grécia e Roma, era enobrecido pela sua qualidade como corante. Este corante ou a sua forma natural, a Índigotina, era extraído directamente de plantas; nos países tropicais, das espécies Índigosfera e em paises temperados das espécies Isatis tinctoria e Polygonium tinctorum. O extracto resultante, consistia numa solução aquosa do glucósido de indoxi-
Io, que era hidrolisado por via fermentativa para dar origem ao Indoxilo, sendo seguidamente oxidado ao ar dando origem ao Índigo, ver esquema 1. [1,2]

A indústria do Índigo conheceu o seu apogeu no início do século XII, com a expansão e colonização promovida pelas nações europeias. No entanto, nos finais do século XIX, esta mesma indústria, baseada na extracção do corante, tornou-se obsoleta, não conseguindo responder ao desafio do índigo sintético. Em 1897, a firma BASF iniciou a comercialização do produto sintético a um preço inferior ao produto de extracção natural. Actualmente, são produzidas cerca de 20,000 toneladas/ano de Índigo sintético, utilizado essencialmente como agente corante dos "blue jeans". [1,2,3]

\section{Sistemas Tautoméricos}

O tautomerismo traduz, em parte, o número de estruturas contributivas para a representação de uma dada molécula.

$\mathrm{O}$ Índigo pode ser facilmente reduzido com uma solução alcalina de ditionito

Esquema 1

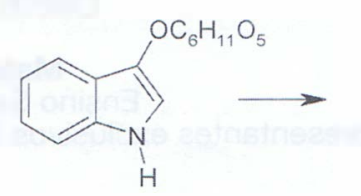

Giucósido de Indoxilo

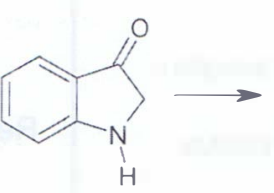

Indoxilo<smiles>O=C1C(=C2Nc3ccccc3N2)C(=O)c2ccccc21</smiles>

Indigo 
Esquema 2<smiles>CC(=O)O[C@H](C(C)=O)c1ccc2c(c1)C([O-])C(=C1Nc3ccccc3C1=O)N2</smiles>

Indigo

de sódio, dando origem a uma estrutura que se pode considerar como uma forma enólica, ver esquema 2.

No caso presente, o tautomerismo traduz-se no equilibrio entre duas estruturas isoméricas, de um composto, que diferem na localização de um átomo de hidrogénio e de uma dupla ligação. O exemplo mais conhecido e comum é o da interconversão entre as formas cetónica e enólica de um composto carbonílico, chamado de tautomerismo cetoenólico. Exemplos concretos deste tipo de equílibrio são encontrados em diversos compostos orgânicos como sejam o caso da 4-metilumbeliferona, da 2 hidroxiflavona, do ácido acetilsalicílico, do 7-azoindole, etc. [4]

Estando o equilíbrio fortemente deslocado para a forma cetónica, a observação da forma enólica é extremamente difícil.

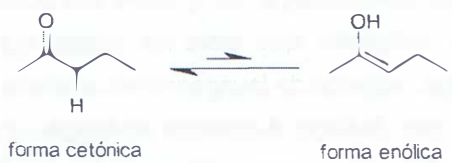

No caso do índigo, dado que as duas espécies podem ser diferenciadas por espectroscopia de UVNis, esta técnica constitui um bom instrumento para a observação das mesmas.

\section{Tingimento com o Índigo}

$\mathrm{O}$ processo de tingimento de um tecido com o Índigo necessita de ser efectuado em meio básico e fortemente redutor. As técnicas tradicionais dependiam dos ritmos lentos da natureza, tanto na formação do Índigo (fermentação), como na obtenção do meio básico (a urina por hidrólise enzimática liberta amoníaco) Em Arraiolos, no início do século $X X$, tingia-se a lã de azul seguindo uma receita onde a urina humana era um constituinte fundamental. O leitor pode deliciar-se com um pequeno trecho de D. José Pessanha, intitulado Tapetes de arraiolos [5].

\section{Azul}

Deita-se o anil (na proporção abaixo declarada) de molho, na véspera, numa tigela ou alguidarinho com agua. No dia seguinte áquelle, se urina num tacho, e vão-se juntando as differentes tachadas, depois de quentes, numa tarefa, asado, ou outro grande vaso de barro, tendo attenção a que se ja liquido suficiente para lhe caber folgada mente a lã que se quer tingir. Nesta urina assim junta e quente, se vae a pouco e pouco lançando a tinta acima do anil, esmagando a pedra ou massa do anil no alguidarinho com uma mão de almofariz até de todo se desfazer, para o que se Ihe vae accrescentando a agua, se tanto é preciso. Mexe-se todo o liquido até ficar nelle a tinta toda distribuida por igual, e conserva-se ao pé do lume, sempre morno. Mette-se- Ihe a lã suja, e como vem da costa da ovelha, mas bem aberta e escolhida, a qual todos os dias se tira para fóra, se espreme, e se põe um pouco ao ar; aquece-se novamente a calda e torna-
se-Ihe a metter a lã; e isto se repete por tantos dias, quantos se jam sufficientes para a lã tomar aquelle azul que se quer. Três dias são de ordinário suficiente; e, se o anil é bom, bastam dois. O bom anil é em pedra e côr de cobre, e tanto melhor quanto mais côr de cobre. Estando a lã tinta, espreme-se, lava-se em agua limpa, e põe-se a enxugar á sombra, porque o sol faz a lã aspera, e só o amarello e talvez o verde se não resentem da influência do sol. E assim fica a lã pronta para se cardar ${ }^{1}$, fiar, desengredar ${ }^{2}$ e fabricar, etc.

Será interessante que o próprio aluno constate a morosidade do processo descrito (dois a três dias), com a celeridade que obtem neste trabalho. Antes da química tinhamos mesmo de esperar pelos recursos fisiológicos...da urina (meio básico que ajuda a dissolução da forma leuco).

O processo de efectuar a redução do Índigo, faz uso do ditionito de sódio (Hidrosulfito de sódio, $\mathrm{Na}_{2} \mathrm{~S}_{2} \mathrm{O}_{4}$ ) em meio básico de acordo com o esquema 3 [6].

\section{Procedimento Experimental}

\section{Síntese do Índigo}

Embora existindo diversos procedimentos de síntese para este composto, o processo seguinte pareceu-nos simples e efectuável num só passo. [7-10]. As

Esquema 3

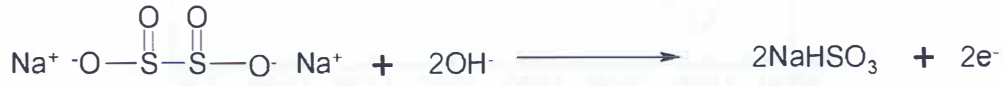


quantidades utilizadas podem obviamente ser proporcionalmente reduzidas, se o pretendido for um trabalho de laboratório em microescala.

Num copo de $100 \mathrm{~mL}$, dissolver $1,0 \mathrm{~g}$ de 2-nitrobenzaldeído em $20 \mathrm{~mL}$ de acetona. Agitar bem e adicionar $\approx 35 \mathrm{~mL}$ de água.

Agitar vigorosamente a solução, com agitador magnético ou simplesmente com uma vareta de agitação, adicionando, gota a gota, $5 \mathrm{~mL}$ de uma solução de $\mathrm{NaOH}(2 \mathrm{M})$. A solução passa de amarelo pálido para escuro, formando-se passados cerca de $30 \mathrm{~s}$ um precipitado escuro, o Índigo.

Continuar a agitar a mistura durante 5 minutos e, seguidamente, filtrar o precipitado por sucção. Lavar o produto com água, até que as àguas de lavagem saiam incolores, e seguidamente com $20 \mathrm{~mL}$ de etanol. Manter o precipitado a secar na trompa durante 10-15 minutos, embrulhar em papel de filtro e levar a uma estufa que esteja a $100-120{ }^{\circ} \mathrm{C}$, durante 30-45 minutos. Pesar o produto e calcular o rendimento.

O mecanismo de síntese do Índigo apresentando-se resumidamente descrito no esquema 4.

\section{Identificação do Índigo em teci- dos}

1) Preparar uma solução aquosa, contendo $1 \mathrm{~g}$ de $\mathrm{NaOH}$ e $\mathrm{lg}$ de ditionito de sódio para um volume total de $50 \mathrm{~mL}$. encontra-se descrito na literatura [3,7],

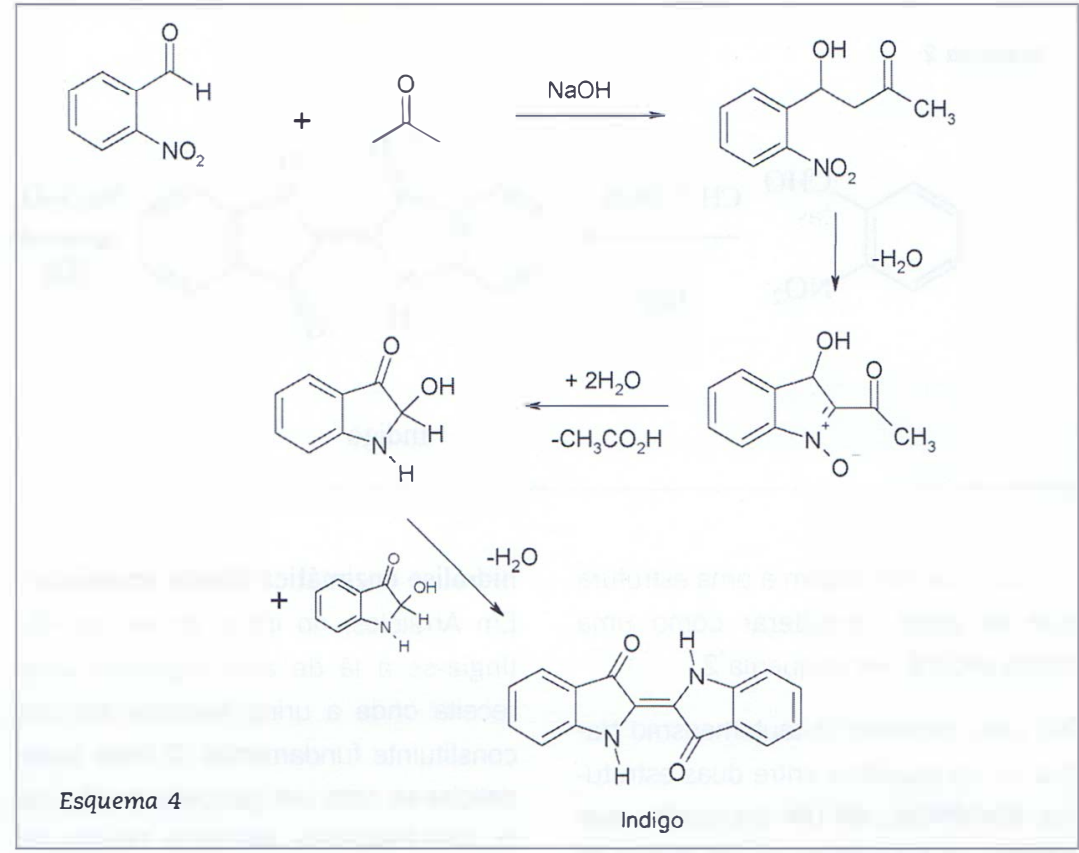

2) Dentro de um tubo de ensaio, colocar algumas tiras de fibras de calças de ganga azul.

3) Adicionar $1 \mathrm{~mL}$ (esta quantidade depende obviamente da quantidade de fibras que introduzir) de solução efectuada em 1). Rolhar o tubo de ensaio. Aquecer, em banho de água, agitando-o, à temperatura de $50-60^{\circ} \mathrm{C}$, durante 5-10 minutos, ou até que a cor azul desapareça

4) Retirar o tubo de ensaio do banho de água e adicionar $1 \mathrm{~mL}$ de etanoato de etilo. Mudar de rolha. Agitar o tubo de ensaio durante alguns minutos. Observar a cor da fase superior (etanoato de

figura 1 Espectro de IV do índigo em $\mathrm{KBr}$ obtido por um aluno. Note-se a elevada quantidade de água presente.

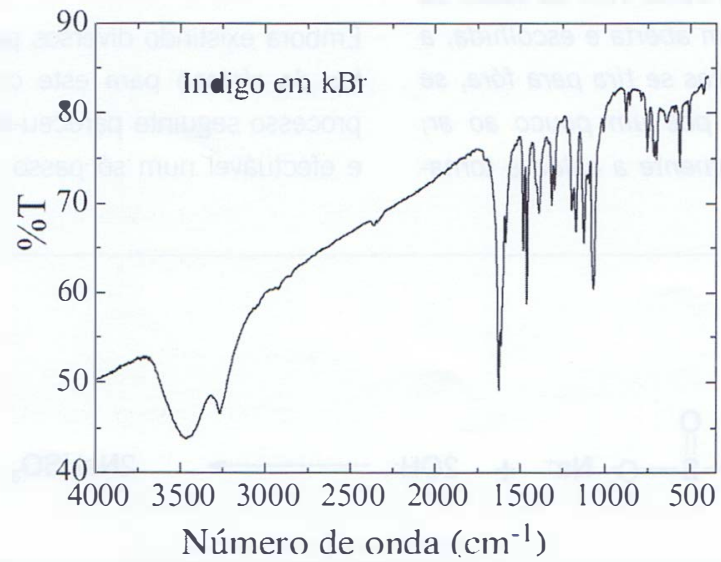

etilo). Se esta for claramente azul, é sinal de que o İndigo está presente.

\section{Estudos Espectroscópicos}

Traçar o espectos de IV dos corantes, que sintetizou, em $\mathrm{KBr}$. Na figura 1 apresenta-se um espectro de FTIR obtido por um aluno após a realização do

Para evitar a presença de água em quantidades que mascarem bandas do próprio composto, é aconselhável que na parte final, após ter pesado o composto para determinação do $\eta$, retire um pouco de composto, que deve ser lavado com água, seguido de lavagem com acetona e de éter dietílico. A correcta atribuição dos modos vibracionais do espectro de IV pode ser encontrada na ref. [11].

O espectro do Índigo pode ser encontrado por simples consulta da base de dados existente na ref. [12], apresentando-se na figura 2, o espectro daí retirado, podendo o aluno efectuar a comparação com o seu espectro.

Traçar os espectros UVNis, das duas formas do İndigo em dimetilformamida, na região dos $650-250 \mathrm{~nm}$. Se os valores de absorvância no máximo forem superiores a 0,8, dilua a solução. Para obter a forma leuco, desareje primeiro, por borbulhamento com Argon ou Azoto, a solução contendo o indigo. protocolo anterior. 


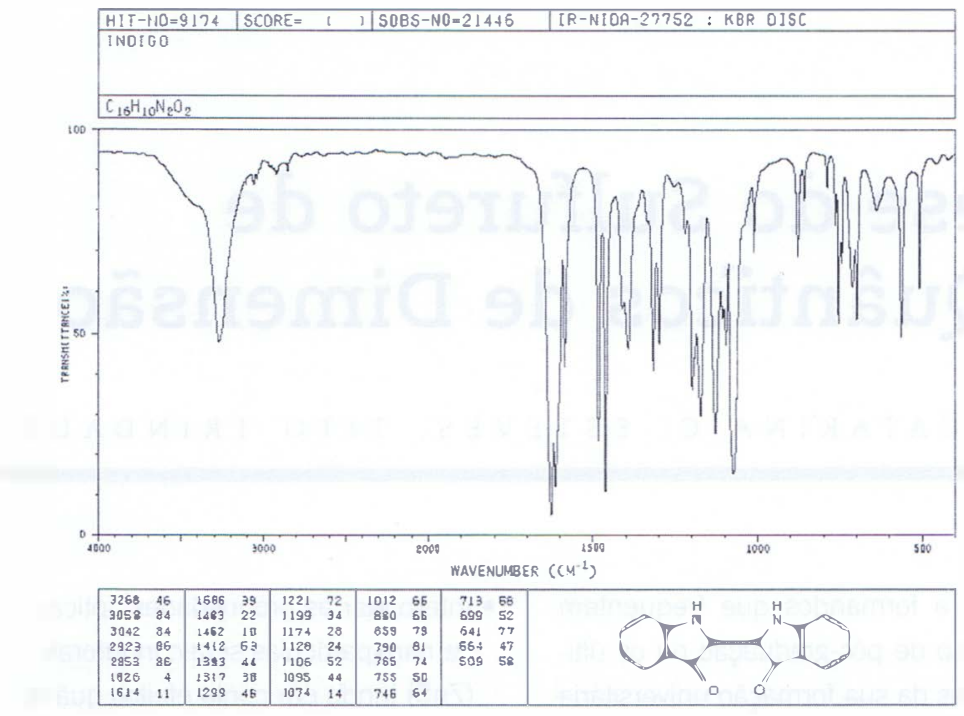

figura 2 Espectro de IV do índigo em $\mathrm{KBr}$ de acordo com a ref. [12].

Seguidamente, com a solução de ditionito de sódio em meio básico, preparada no ponto anterior, adicione gota a gota(normalmente uma gota da solução anterior é suficiente) até observar o aparecimento de uma cor amarela.

Os espectros de absorção UVNis das formas ceto e leuco do Índigo encontram-se representados na figura 3

O reaparecimento da cor azul característico da forma ceto do Índigo pode ser observado pelo simples traçar do espectro de absorção da forma leuco ao longo do tempo, deixando para isso aberta a cuvete de absorção.

figura 3 Espectros de absorção UV/Vis das formas ceto e leuco do índigo

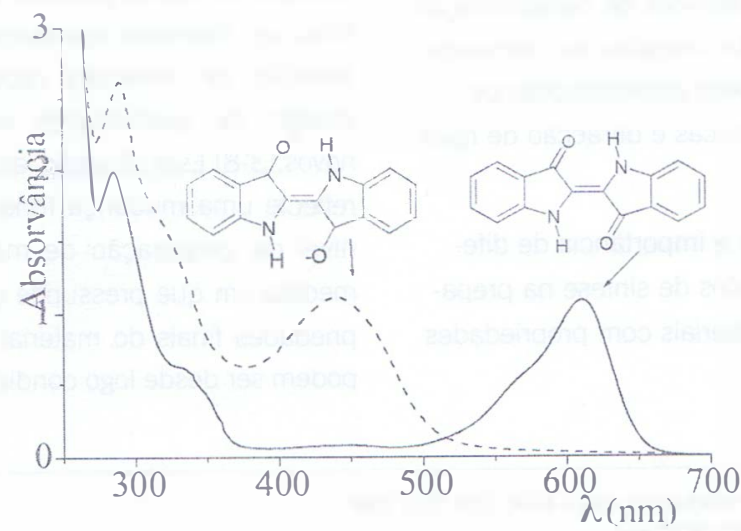

Mergulhe, nesta solução, o pano de algodão que pretende tingir. Faça-o rapidamente e rolhe de imediato o tubo de ensaio. Aqueça a $50-60{ }^{\circ} \mathrm{C}$ durante alguns minutos, 2 a 15 min, consoante a intensidade de azul desejado. Retire o pano de algodão e deixe-o secar ao ar. A cor azul, aparecerá gradualmente, como por magia. Um procedimento mais detaIhado pode ser encontrado na ref. [13]

\section{Agradecimentos}

Aos alunos da licenciatura em Química da FCTUC, disciplina de Laboratórios de Química IV (ano de 2000/2001), pela motivação e gosto com que realizaram este trabalho. Em parte foi por eles que decidimos publicar este trabaIno. À Doutora Maria João Melo pela leitura e sugestões críticas e generosas para com este trabalho.

\section{Bibliografia}

[1] R. J. H.Clark, C. J. Cooksey, M. A. M Daniels e R. Withnall, Endeavour (1993), 17(4), 191.

[2] N. Torimoto, J. Chem. Educ. (1987), 64(4), 332

[3] R. J. H.Clark, C. J. Cooksey, M. A. M. Daniels e R. Withnall, Educ. Chem. 1996, 16

[4] J. Seixas de Melo, Tese de Doutoramento, Lisboa, 1996

[5] José Pessanha, Separata d' "O Archeolo. go Português", XI, n. ${ }^{\circ}$ S 5 a 8 de 1906.

[6] Modern Organic Chemistry, J. D. Roberts e M. C. Caserio, W. A. Benjamin Inc., 1967

[7] http://schools.wcpss.net/EastWakeHigh/ Departments/Science/synthesis.htm

[8] B. T. Golding e C. Pierpoint, Educ. Chem (1986) 71.

[9] A. Bayer, Ber. 11 (1878) 2128.

[10] J. R. McKee e M. Zanger, J. Chem Educ. (1991) 68, A242

[11] E. Tatsch e B. Schrader, J. Raman Spectrosc., (1995) 26, 467

[12] http://mww.aist.go.jp/RIODB/SDBS/ menu-e.htm

[13] D. W. Boykin, J. Chem. Educ. 75, 769 (19э8) 